\title{
CORRESPONDENCE
}

\section{Subacute posttraumatic ascending myelopathy: a literature review}

Spinal Cord Series and Cases (2017) 3, 17012; doi:10.1038/ scsandc.2017.12; published online 27 April 2017

We read with great interest the article by Drs Zhang and Wang reviewing subacute posttraumatic ascending myelopathy (SPAM). ${ }^{1}$ We recently reported a case of SPAM ${ }^{2}$ that was not included in their paper, likely due to timing of publication. We also conducted a literature review, which drew many of the same conclusions as Drs Zhang and Wang's paper.

Drs Zhang and Wang's review contains images, though no detailed description, of a case they previously reported. ${ }^{3}$ This case is interesting especially in that the patient described presumably died as a result of respiratory depression from SPAM affecting the cervical spinal cord. We are not aware of another case of mortality directly attributed to SPAM.

SPAM is a rare and potentially catastrophic complication of spinal cord injury $(\mathrm{SCl})$. Though more common after complete $\mathrm{SCl}$, our patient developed SPAM after a mild SCl. Drs Zhang and Wang's paper further emphasizes the need for physicians to be vigilant for this entity as there are likely many unreported cases.

\section{COMPETING INTERESTS}

The authors declare no conflict of interest.

Brandon A Miller ${ }^{1}$ and Faiz U Ahmad ${ }^{2}$ ${ }^{1}$ Department of Neuorsurgery, Washington University in St Louis, St Louis, MO, USA and

${ }^{2}$ Department of Neurosurgery, Emory University, Atlanta, GA, USA Correspondence: BA Miller (millerb@wudosis.wustl.edu)

\section{REFERENCES}

1 Zhang J, Wang G. Subacute posttraumatic ascending myelopathy: a literature review. Spinal cord (e-pub ahead of print 20 December 2016; doi:10.1038/ sc.2016.175).

2 Miller BA, Roy AK, Boucher AB, Pradilla G, Ahmad FU. Subacute posttraumatic ascending myelopathy after an incomplete spinal cord injury from a gunshot wound to the spine: case report and review of the literature. World Neurosurg 2016; 88: e13- e17.

3 Zhang J, Wang HL, Liu HY, Wang GS. Subacute post-traumatic ascending myelopathy after T12 burst fracture in a 32-year-old male: case report and surgical result of cervical durotomy. Spinal Cord Ser Cases 2016; 2: 16004. 